\title{
DEZ VEZES SEM JUROS: UMA ANÁLISE DOS MECANISMOS DE PERSUASÃO UTILIZADOS NA PUBLICIDADE DE VAREJO
}

\author{
Clearance sale: analysis of persuasion mechanisms in retail \\ advertising
}

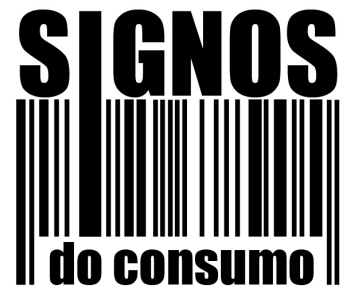

artigo

\section{Rebajas: análisis de los mecanismos de persuasión utilizados por la publicidad al por menor}

\author{
José Maria Melim \\ Universidade Sociedade Educacional de Santa Catarina, Santa Catarina, Brasil. \\ Professor no Programa de Pós-Graduação em Engenharia de Produção da Universidade Sociedade Educacional \\ de Santa Catarina. Doutor em Engenharia de Produção pela Universidade Federal de Santa Catarina. \\ E-mail: melim.joi@terra.com.br
}

\section{Mauricio José Melim}

\author{
Associação Educacional Luterana Bom Jesus, Santa Catarina, Brasil. \\ Professor dos cursos de Publicidade e Propaganda e Jornalismo na Associação Educacional Luterana Bom Jesus. \\ Mestre em Ciências da Comunicação pela Universidade do Vale do Rio dos Sinos. \\ E-mail: mauricio.melim@ielusc.br
}

RESUMO Este trabalho oferece um ensaio analítico acerca da persuasão em publicidade. O arcabouço teórico utilizado conjuga conceitos de psicologia social e semiótica, e o alvo da análise é um típico anúncio de varejo. Busca-se nele identificar a presença de certos mecanismos psicológicos de persuasão e, em seguida, descrever o modo como esses mecanismos estão materializados no anúncio, sob a forma de signos figurativos, linguísticos e plásticos.

PALAVRAS-CHAVE Persuasão, Publicidade, Varejo, Psicologia social, Semiótica.

\begin{abstract}
This article provides an analytical essay on persuasion in advertising. The theoretical framework combines concepts of social psychology and semiotics, and the object of analysis is a retail ad. This work seeks to identify the presence of certain psychological mechanisms of persuasion, and then it describes how these mechanisms have been embodied in the ad, in the form of figurative signs, linguistic signs and plastic signs.
\end{abstract}

KEYWORDS Persuasion, Advertisement, Retail, Social psychology, Semiotics.

RESUMEN Este documento presenta un ensayo analítico sobre la persuasión en la publicidad. El marco teórico utilizado combina los conceptos de la psicología social y la semiótica, y el objetivo del análisis es un anuncio típico minorista. El propósito es identificar la presencia de ciertos mecanismos psicológicos de persuasión y describir cómo se incorporan estos mecanismos en el anuncio, en forma de signos linguísticos, plásticos y figurativos.

PALABRAS CLAVE Persuasión, Publicidad, Venta al por menor, Psicología Social, Semiótica. 


\section{PUBLICIDADE E PERSUASÃO}

A persuasão publicitária se efetiva porque os anúncios abarcam certos mecanismos discursivos de ordem psicossocial, mecanismos que incidem sobre a afetividade. A proposta deste trabalho é mostrar como esses mecanismos, chamados de princípios persuasivos, funcionam no dia a dia. Para isso, analisou-se um anúncio com o intuito de identificar quais princípios persuasivos abordam e descrevê-los semioticamente.

A persuasão será entendida, neste estudo, como esforço de comunicação para influenciar a atitude e o comportamento do consumidor (Shimp, 2002). Nessa definição, influenciar a atitude do consumidor significa criar em sua mente uma imagem positiva do produto anunciado. E ao influenciar o comportamento instiga-se o consumo efetivo (Shimp, 2002).

A metodologia adotada concentra-se sobre o potencial persuasivo da mensagem. Essa perspectiva assume como pressuposto o fato de que a mensagem constitui, no processo comunicativo, um componentechave. Um componente que pode incutir no público determinadas ideias e levar a determinadas ações. Com essas considerações não se deseja criar uma ponte direta entre estímulo e resposta. A publicidade se destina a seres humanos, seres históricos, que não respondem todos da mesma maneira.

A análise do anúncio contempla dois movimentos. O primeiro visa identificar na mensagem a presença de certos princípios persuasivos de caráter psicossocial. O segundo movimento consiste em uma análise semiótica desses princípios.

\section{MECANISMOS PSICOSSOCIAIS DE PERSUASÃO}

Como ocorre a persuasão? Essa é sem dúvida uma questão central para a publicidade. E foi sobre ela que se debruçou Cialdini (2012) para concluir que existe um conjunto relativamente pequeno de mecanismos persuasivos atuando nas mensagens da publicidade e de profissionais de vendas. A base desses mecanismos são afetos e normas sociais que perfazem o ser humano.

Existe ainda outro ingrediente importante e mais amplo dentro dessa lógica, o atual modo de vida acelerado. Sem tempo para refletir sobre as inúmeras demandas cotidianas, a saída utilizada pela maior parte das pessoas é ater-se a algum atalho, alguma informação que aponte rapidamente para a decisão correta.

Exemplo introdutório do que é um atalho e como se manifesta na experiência cotidiana é o seguinte: "Um princípio conhecido do comportamento humano afirma que, ao pedirmos um favor a alguém, teremos mais sucesso se fornecermos um motivo." (Cialdini, 2012, p. 15). Nesse caso tão corriqueiro, a explicitação do motivo, da razão que justificaria o pedido está agindo como atalho que aumentará as chances de obter uma resposta positiva.

Segue uma breve apresentação de cada um dos seis princípios persuasivos considerados por Cialdini (2012) como os mais utilizados e eficazes.

Princípio da reciprocidade. Este princípio põe em relevo uma norma social segundo a qual toda ajuda ou favor precisa ser retribuído. Um caso desse princípio no marketing é a tática de oferecer brindes, 
benefícios e até mesmo a gentileza do vendedor. Embora o princípio pareça mais a fim às comunicações face a face é possível pensá-lo também em anúncios. Por exemplo, mensagens que lembram aos filhos quão difícil é ser pai ou mãe, para em seguida apresentar-lhes uma oportunidade de retribuição, uma joia, um perfume.

Princípio do compromisso e coerência. Tende a funcionar por um tipo de injunção social, que valoriza aqueles que respeitam seus compromissos e mantêm uma linha coerente em seus discursos e comportamentos, e ao mesmo tempo reprova aqueles que atuam na direção contrária. Nos anúncios esse princípio pode aparecer em mensagens que tratam do passado do público-alvo, lembrando sua trajetória, como agiu e pensou, e como essa trajetória deve ser mantida na hora de comprar um carro novo, renovar o seguro, o plano de saúde.

Princípio da aprovação social. As risadas de fundo usadas em seriados cômicos são geralmente consideradas falsas, idiotas, tanto por aqueles que produzem quanto por quem assiste a esses programas. $\mathrm{O}$ dado curioso é que essas risadas contribuem para a graça dos seriados, fazendo que o público ria por mais tempo e mais vezes. Segundo Cialdini (2012), esse efeito tem a ver com o princípio da aprovação social, que aparece quando o indivíduo se espelha na opinião ou no comportamento do grupo para agir ou tomar uma decisão. $\mathrm{Na}$ publicidade esse princípio aparece, por exemplo, nas mensagens com depoimentos ou naquelas em que modelos estão simplesmente usufruindo o produto.

Princípio da afeição. Existe uma ligação muito estreita entre o desempenho do persuasor e sua aparência física. O personagem considerado belo tem muito mais chances de convencer o público (Cialdini, 2012). Mas a afeição pode desenvolver-se também quando o personagem mimetiza algo de seu público, seja opinião, características étnicas, status. Em anúncios é fácil encontrar tanto a modelo de beleza inatingível, a funcionar como ideal, quanto o personagem-metonímia de determinado grupo.

Princípio da autoridade. Segundo esse princípio, existe um impulso a fazer que as pessoas deem mais atenção a quem lhes parece imponente, inteligente. Se nessa linha o princípio soa negativamente, é preciso conhecer também o outro lado, que tem a ver com a complexidade da vida moderna e a necessidade de especialistas mediadores. Assim, as pessoas confiam no médico, no mecânico automotivo, no pessoal de TI, porque se sentem inaptas a resolver dado problema. Não é preciso dizer que a publicidade faz uso assíduo desse princípio: dentistas nos anúncios de higiene bucal, atletas anuciando artigos esportivos etc.

Princípio da escassez. Segundo este princípio, "as pessoas atribuem mais valor a oportunidades quando estas estão menos disponíveis." (Cialdini, 2012, p. 262). Essa lógica é posta em ação quando há raridade, censura, limite e dificuldade de obtenção. Na publicidade esse princípio se manifesta nas liquidações, nas ofertas e condições de pagamento por tempo limitado. Mas pode se expressar também sob o signo da restrição, como nos casos de produtos de alto custo, exclusivos etc.

Ao se analisar a publicidade tendo como referência teórica esse conjunto de princípios, o que se pode revelar é uma das possíveis causas de sua persuasividade ou de seu poder de influência. 


\section{ELEMENTOS DE SEMIÓTICA}

Esta seção oferece alguns recursos semióticos que servirão adiante para descrever como, no anúncio analisado, determinados princípios persuasivos foram construídos.

O quadro utilizado aqui mostra que os anúncios visuais são constituídos por três registros: o figurativo, o linguístico e o plástico (Joly, 2010). Evidentemente desconsideram-se anúncios sonoros e audiovisuais. Integra o registro figurativo qualquer imagem e ilustração que encontram equivalentes ou aproximáveis fora do próprio anúncio, como pessoas, produtos, locais, personagens. O registro linguístico abarca todo tipo de construção verbal presente no anúncio. Ao passo que o registro plástico inclui tudo aquilo que não é exatamente figurativo nem linguístico, embora esteja muito intimamente ligado a esses. Na proposta de Joly (2010), fazem parte desse registro as cores, as formas, as texturas e a espacialidade (este último abarca dimensão relativa dos elementos, posição no espaço, proximidade relativa, entre outros).

Essa divisão em registros propicia um olhar mais atento e rigoroso sobre cada um dos constituintes do anúncio, olhar que permite entender sua participação na mensagem. Classificar signos é uma tarefa corriqueira em semiótica. Um dos propósitos desse empreendimento é fazer notar que signos diferentes tendem a produzir significados também diferentes. Os signos linguísticos, por exemplo, geralmente são lembrados por seu poder de especificação (Vestergaard; Schroder, 2000), quando comparados aos signos figurativos e aos signos plásticos. Como dizer tudo em dez vezes sem juros com imagens e/ou com formas abstratas? Por sua vez, o figurativo e o plástico podem servir para sugerir e incutir ideias e sensações sem que o intérprete saiba exatamente como ou por que isso ocorreu. A divisão dos registros sígnicos e seu tratamento em separado, no entanto, não podem ignorar que se de um lado as partes detêm alguma autonomia em termos de significação, por outro precisam ser consideradas no seu conjunto, na sua interdependência e inter-relação.

Outro modo de dizer algo sobre o poder de atuação dos signos é pelo par denotação/conotação (Joly, 2010). Trata-se de dois modos de significação, sendo que o primeiro diz respeito àquelas mensagens que são geralmente interpretadas de forma precisa, direta e sem ambiguidade. Na outra mão está o regime conotativo, que tende a produzir uma interpretação mais ampla, sinuosa, ambígua, pouco objetiva. A imagem fotográfica de uma maçã pode ser apenas uma fruta em uma leitura denotativa. Mas a mesma imagem conotativamente pode sugerir beleza e sensualidade.

\section{VAREJO: PUBLICIDADE INTENSA E COTIDIANA}

O termo "varejo" designa uma ampla categoria de atuação comercial da qual são exemplos as lojas de departamento, os outlets, os supermercados, as lojas de conveniência, as lojas virtuais, as máquinas de vendas. A característica que unifica todos esses casos é o contato com o consumidor final (Las Casas, 2013). A publicidade de varejo pode servir para fixar e consagrar a imagem da empresa, como aponta Sant’Anna (2014), mas provavelmente os anúncios 
mais lembrados dessa categoria são aqueles de estímulo direto às vendas, de supermercados e magazines, que apresentam uma série de produtos com seus preços promocionais. Em geral, a linguagem desse tipo de anúncio não tem charme nem glamour (Martins, 2004), mas ainda assim parece funcionar. No Brasil, o varejo é o setor que mais investe na veiculação de anúncios (Ibope Media, 2014). Esse é um dado importante porque indicia um contato acentuado do setor com o consumidor, o que por sua vez amplia as chances de persuasão. O varejo é persistente, seus anúncios são contínuos, não sazonais, além disso estão presentes praticamente em todas as mídias.

Da presença maciça na mídia é possível fazer outra inferência: aquilo que ocorre ou aparece com frequência tende a naturalizar-se, a se tornar parte da normalidade, e isso decerto ocorre com o anúncio de varejo. Por ser cotidiano e aparentemente pobre em termos de estratégia discursiva esse anúncio pode parecer inócuo aos olhos do consumidor. Nas análises procura-se demonstrar que mesmo essa classe de publicidade pode conter mecanismos de influência.

\section{PERSUASÃO NA PUBLICIDADE DAS LOJAS BREITHAUPT}

Nesta seção coloca-se em ação aquilo que foi dito nas linhas precedentes. A proposta é fazer uma leitura do processo persuasivo em um anúncio publicitário concreto.

Este artigo é parte de um estudo que vem sendo realizado na cidade de Joinville, Santa Catarina, sobre a publicidade regional. Vem daí a escolha do anúncio analisado, que privilegiou anunciante (lojas Breithaupt) e veículo (jornal A Notícia) locais.

A rede Breithaupt conta com mais de oitenta e cinco anos de atuação e é um dos maiores varejistas do segmento construçãoreformas-decoração de Santa Catarina, estando presente em Jaraguá do Sul, Guaramirim, Joinville, Itajaí, Brusque, Timbó, São Bento do Sul, Mafra e Canoinhas. A rede comercializa, entre outros produtos, materiais de construção, máquinas e ferramentas diversas, eletrodomésticos, móveis, artigos de bazar e automotivos. Segundo o Top of Mind 2014, Breithaupt é uma das empresas mais lembradas pelos catarinenses (Breithaupt, 2015). O jornal A Notícia é também uma empresa tradicional e importante no estado, que conta agora com mais de noventa anos de atuação e é líder em circulação no norte e nordeste de Santa Catarina (Grupo RBS, 2014).

O anúncio analisado (Figura 1) é um típico anúncio de varejo: apresenta um leque de produtos com seus preços e condições de pagamento, além de um garoto-propaganda que parece agir como apresentador e incentivador da compra. 


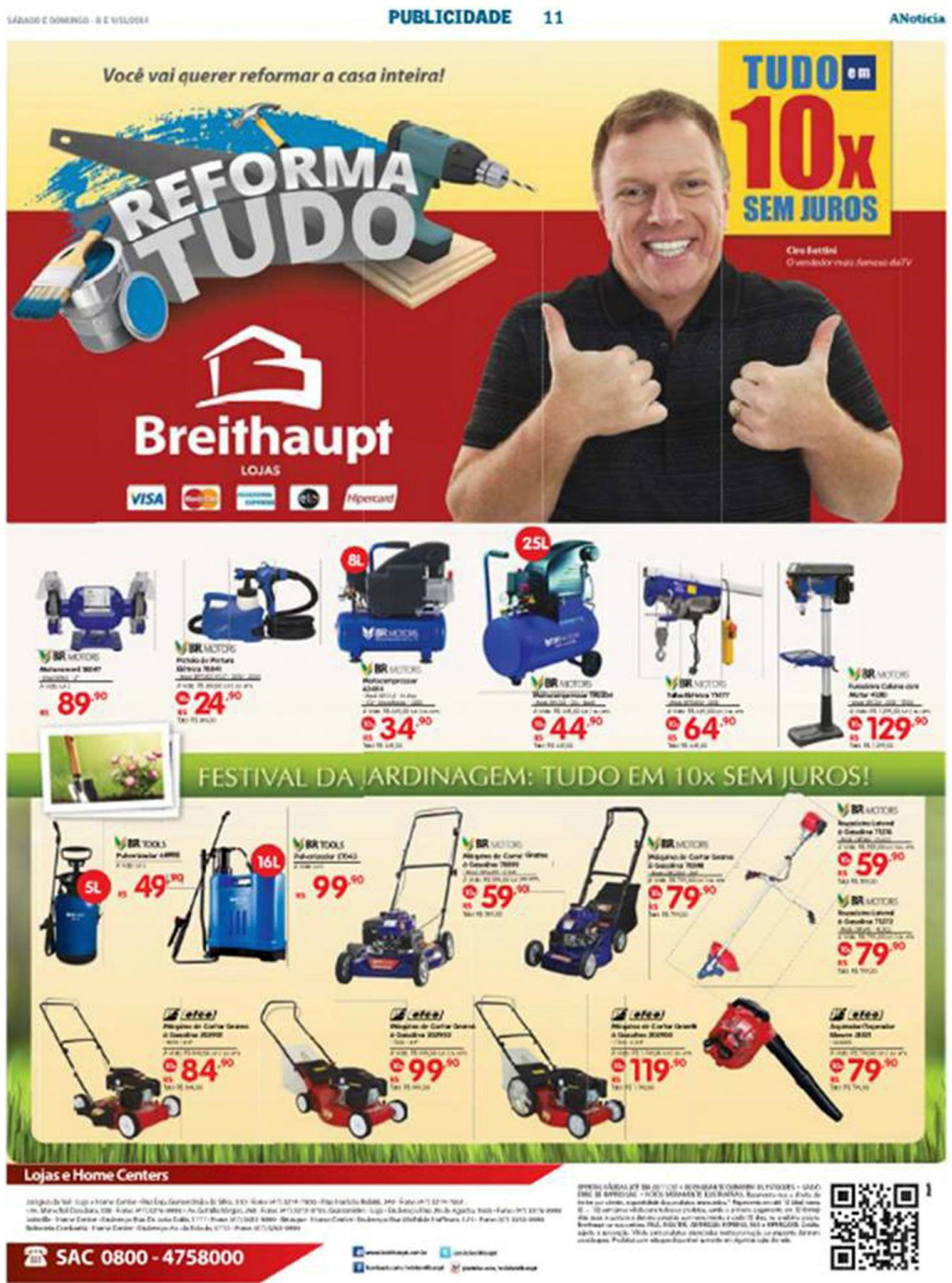

Figura 1. Anúncio da loja Breithaupt.

Fonte: A Notícia (2014).

\section{Princípios persuasivos}

Uma boa indagação de partida acerca da Breithaupt seria: há algo de persuasivo neste anúncio tão simples e pobre em criatividade? De fato, muitos dos artifícios usados pela publicidade para chamar a atenção e despertar o interesse do público (Solomon, 2011) parecem estar ausentes nessa peça. Não há imagens estranhas e impactantes nem título provocativo, por exemplo. Não há nada de criativo ou inovador na configuração geral. E tampouco há cenas de humor ou insinuações eróticas. No entanto, se se considera o quadro teórico dos princípios persuasivos, é possível encontrar pelo menos dois mecanismos de influência neste anúncio, que são o princípio da escassez e o princípio da afeição. O primeiro aparecendo de forma mais enfática que o segundo.

O princípio da escassez diz que as pessoas tendem a valorizar aquilo que é raro, difícil de acessar, ou aquilo que pode assumir essas condições a qualquer momento. Muitos anúncios de varejo fazem uso 
desse princípio quando tentam levar a crer que os bens anunciados logo esgotarão ou, como é provável no caso da Breithaupt, que aqueles bens com aqueles preços e condições de pagamento dificilmente serão vistos de novo.

Este anúncio conta também com o princípio da afeição, cujo elemento-chave é o garoto-propaganda Ciro Bottini. Esse princípio afirma que a influência tende a se efetivar com mais facilidade quando o persuasor é alguém conhecido e/ou visto com simpatia. Ciro Bottini não é exatamente uma celebridade, mas ainda assim é um rosto com presença frequente na publicidade televisiva, o que pode desencadear no público alguma afeição.

\section{Semiótica dos princípios persuasivos}

Quando se trata de discutir sobre a manifestação do princípio da escassez em uma peça publicitária, o mero reconhecimento geral, seu layout, como sendo de varejo é importante. Isso porque tão logo se realize esse reconhecimento estará acionando o atalho mental que diz se tratar de uma oportunidade, uma chance única e imperdível.

O layout do anúncio de varejo frequentemente é constituído por diversos produtos apresentados de forma sumária e sem grandes descrições nem elogios. É o que se encontra na peça da loja Breithaupt.

De modo mais imediato, são os registros plástico e figurativo que propiciam o reconhecimento da peça como de varejo. Mas o registro linguístico tem também um papel fundamental para a expressão do princípio da escassez.

O modo serial como estão dispostos os produtos na peça diz respeito à categoria da espacialidade, pertencente ao registro plástico. Essa serialidade é um traço marcante do layout de varejo. Antes mesmo de focalizar os produtos, o público provavelmente já tem alguma ideia de que tem diante de si um anúncio de promoções. Desse modo, está-se sugerindo que em termos de representação do princípio da escassez a quantidade de produtos à mostra é mais relevante do que o reconhecimento dos produtos em si.

Há outro ponto importante do registro plástico que se relaciona com o princípio da escassez. E esse ponto acaba envolvendo o registro figurativo. No anúncio da loja Breithaupt tudo é mostrado com clareza, os produtos, o personagem e a parte linguística em geral (é importante frisar que o registro plástico constitui e perpassa tudo que há no anúncio, inclusive os dois outros registros). Clareza aqui significa que aqueles elementos não se sobrepõem ou se fundem e nem se mesclam com o plano de fundo. Tudo é bem delineado e cada elemento tem seu espaço, ficando perfeita e objetivamente visível.

Esse modo denotativo, direto e franco, de apresentação dos elementos contém uma mensagem, mesmo que não seja percebida de forma consciente pelo público. Breithaupt não conta história nem anedota alguma e não pede que admirem ou reflitam sobre os produtos. Sua objetividade não dá margem à fantasia e divagação. Portanto, a mensagem é: não há tempo para distrações, vamos ao que interessa, vamos à ação! Nessa ótica, o modo direto de apresentar os produtos funciona como reforço do princípio da escassez.

Quanto ao registro figurativo, pode-se indicar a presença do garotopropaganda como coajuvante na representação da escassez. Essa presença por si só não denota o princípio da escassez, mas vincula-se a ela. Isso 
ocorre porque se tornou parte da linguagem do varejo estabelecer uma identidade entre anunciante e um personagem específico. $O$ registro linguístico, embora tenha relativamente pouco destaque, possui um papel essencial para a realização do princípio da escassez. É preciso esclarecer que essa consideração vale apenas para aqueles signos linguísticos que representam preço e condições de pagamento. Esses componentes têm uma atuação dupla: primeiro também reforçam a ideia de varejo e, segundo, levam a crer que preços e condições não são os de sempre, mas promocionais e efêmeros. Enfim, esses elementos reforçam a sensação de oportunidade única. Vale notar ainda que o princípio da escassez, embora evidente, não foi explicitado de modo linguístico na peça: não há frases como 'oportunidade única', 'últimas peças', 'preços assim nunca mais’ etc. Além do princípio da escassez, essa peça recorre ao princípio da afeição para persuadir seu público. $O$ elemento central na representação desse princípio é a imagem do garoto-propaganda Ciro Bottini; portanto, configurando-se o registro figurativo.

Antes de participar das campanhas da Breithaupt, Bottini já era conhecido como apresentador do canal de vendas Shoptime. É, portanto, uma figura popular, conhecida do público, e essa é uma das características-chave para o acionamento do princípio da afeição. Um endossante familiar tende a tornar a mensagem mais atrativa e confiável, diz esse princípio (Cialdini, 2012). O princípio da afeição, no entanto, é secundário nesse anúncio se comparado ao princípio da escassez. Faz-se essa afirmação levando em conta a área ocupada pelo personagem em relação ao espaço total da página - trata-se aí de um aspecto que lida tanto com o registro figurativo quanto com o registro plástico (tamanho relativo dos elementos). É fácil perceber que a maior parte do anúncio está ocupada pelas ofertas, os produtos e seus preços. O grau de popularidade do personagem é outro fator que secundariza o princípio da afeição nessa peça. Apesar de familiar, Bottini provavelmente não tem o mesmo grau de popularidade e simpatia que, por exemplo, artistas de telenovelas e outras celebridades. A afeição, assim, pode aparecer, mas será decerto moderada.

Sobre o personagem e sua relação com a afeição existem ainda duas outras observações. Estudos em psicologia e neurociência constataram que o uso de figuras humanas na publicidade pode aumentar as chances de captura da atenção e do interesse do público e, além disso, auxiliar na memorização da peça (Pradeep, 2012). No caso de celebridades, os efeitos podem ser ainda mais acentuados e amplos. Por exemplo, as marcas e produtos podem assumir de modo simbólico algumas das características da personalidade endossante, como beleza, sensualidade, juventude, credibilidade, simpatia, glamour etc. (Shimp, 2002). A simples presença de pessoas no anúncio, portanto, pode ampliar o poder de persuasão deste.

A segunda ideia atrelada a essa primeira salienta que a parte mais chamativa do corpo humano é o rosto, e a parte mais chamativa do rosto são os olhos (Pradeep, 2012). Na publicidade, essas constatações se transformam em estratégias de captura da atenção do público. No emaranhado de estímulos visuais de um site, jornal, revista, o rosto tende a ser um elemento de forte atração. Ciro Bottini, o garoto-propaganda da Breithaupt, mira diretamente o leitor, como se estivesse falando com ele, querendo aproximar-se dele. Esse olhar é interpretado aqui como uma configuração que pode contribuir para o desenrolar da afeição. 
Por fim, a participação do registro linguístico na representação da afeição é praticamente nula. "Reforma tudo", "Você vai querer reformar a casa inteira", "Tudo em 10X sem juros" e "Festival da jardinagem: tudo em 10X sem juros!” podem ser atribuídos ao personagem, ainda que essa conexão não seja explícita. Mas nenhuma dessas falas mantém uma relação direta com a noção de afeição. Elas servem muito mais ao princípio da escassez.

\section{CONSIDERAÇÕES FINAIS}

Afinal, como funciona a persuasão na loja Breithaupt? Pela análise empreendida, a estratégia persuasiva da Breithaupt baseia-se em dois mecanismos, o princípio da escassez e, em menor dose, o princípio da afeição. O anúncio, portanto, procura criar uma atmosfera de oportunidade única e imperdível e, de modo menos incisivo, criar uma espécie de laço com o consumidor por meio de uma figura de rápido reconhecimento.

É interessante atentar para o fato de que o princípio da escassez de certo modo transporta o consumidor para além dos produtos anunciados. Dito de outra forma, o anúncio, é claro, propõe-se a vender um objeto concreto, mas o que leva o consumidor a adquiri-lo é menos o produto em si e mais a chance de comprá-lo naquele momento.

Quando tomado o princípio da escassez sob a lente semiótica aparecem pelo menos duas questões interessantes. A primeira está relacionada ao layout do anúncio, que se mostra como um típico anúncio de varejo, isto é, com múltiplos produtos e seus preços em destaque, organização que remete diretamente à noção de promoção, liquidação e oportunidade. Note-se que para essa interpretação não importa o tipo de produto, sua marca, o que importa é a quantidade e a disposição dos objetos.

A segunda questão diz respeito ao caráter predominantemente denotativo da peça, o que também corrobora a noção de escassez. Os produtos aparecem de forma clara e direta. Os textos do anúncio são todos literais e objetivos, não há ambiguidade ou trocadilhos. Não há, portanto, nas imagens ou nos textos desvios ou digressões imaginárias, e a mensagem implicada aí (e talvez mais sentida que interpretada) é a de que o importante é ver, ler o principal e agir, sem rodeios.

Nessa linha, talvez valha a pena um último comentário. No meio publicitário, a criatividade é tratada como ideal a perseguir. Os professores na academia incentivam e cobram dos estudantes o desenvolvimento de soluções novas, instigantes e originais. Os manuais da área insistem nessa mesma questão. E há ainda os festivais, que celebram e premiam as campanhas mais criativas.

A justificativa para esse fato é a crença de que a campanha criativa tende a obter melhores resultados. Como disse o publicitário Stalimir Vieira (2001, p. 26), “um anúncio criativo pode até custar mais que um convencional, em compensação será sempre mais eficiente.” Mas é preciso dizer que há também quem relativize essa crença (Belch; Belch, 2014), e é nessa linha que se inscreve este estudo. A intenção ao se resgatar essa discussão é lembrar que a ênfase demasiada na criatividade pode levar a crer que só o anúncio criativo, por sua inteligência, originalidade ou beleza contém mecanismos persuasivos. As páginas anteriores, acreditase, demonstraram que mesmo em um anúncio de varejo típico, com todos os seus estereótipos, é possível encontrar elementos persuasivos. 


\section{REFERÊNCIAS}

A NOTíCIA. Joinville, ano 91, ed. 26762, p. 11, 2014

BELCH, G. E.; BELCH, M. A. Propaganda e promoção: uma perspectiva da comunicação integrada de marketing. 9. ed. Porto Alegre: AMGH, 2014.

BREITHAUPT. Disponível em: <http://bit.ly/2oNdymN>. Acesso em: 21 jul. 2015.

CIALDINI, R. B. As armas da persuasão. Rio de Janeiro: Sextante, 2012.

GRUPO RBS. A Notícia. 2014. Disponível em: <http://comercial.gruporbs.com.br/veiculos/a-noticia/>. Acesso em: 18 dez. 2014.

IBOPE MEDIA. Retro perspectiva: investimento publicitário 2014. Disponível em: <http:// bit.ly/209Mf2Z>. Acesso em: 25 ago. 2015.

JOLY, M. Introdução à análise da imagem. 10. ed. Campinas: Papirus, 2010.

LAS CASAS, A. L. Marketing de varejo. 5. ed. São Paulo: Atlas, 2013.

MARTINS, Z. Propaganda é isso aí: um guia para novos anunciantes e futuros publicitários. São Paulo: Atlas, 2004.

PRADEEP, A. K. O cérebro consumista. São Paulo: Cultrix, 2012.

SANT'ANNA, A. Propaganda: teoria, técnica e prática. 8. ed. São Paulo: Cengage Learning, 2014.

SHIMP, T. A. Propaganda e promoção: aspectos complementares da comunicação integrada de marketing. Porto Alegre: Bookman, 2002.

SOLOMON, M. R. Comportamento do consumidor: comprando, possuindo e sendo. 9. ed. Porto Alegre: Bookman, 2011.

VESTERGAARD, T.; SCHRODER, K. A linguagem da propaganda. São Paulo: Martins Fontes, 2000.

VIEIRA, S. O raciocínio criativo na publicidade: uma proposta. 2. ed. São Paulo: Loyola, 2001. 